\title{
Pragmatic Realism*
}

Hasok Chang $^{* * *}$

\begin{abstract}
In this paper I seek to articulate and develop Roberto Torretti's advocacy of pragmatic realism. At the core of Torrietti's view is a rejection of the notion that the truth of scientific theories consists in their correspondence to the world. I propose to understand correspondence in that sense as a metaphorical notion. I articulate a notion of pragmatist coherence, on the basis of which I make new coherence theories of truth and reality. Then it becomes possible to say that pragmatic realism consists in the pursuit of true knowledge of reality, in a way that is also consonant with Torretti's pluralism.
\end{abstract}

Keywords: pragmatism, realism, pluralism, coherence, truth, reality

\section{Realismo Pragmático}

\section{Resumen}

En este trabajo intento articular y desarrollar la defensa que Roberto Torretti hace del realismo pragmático. En el núcleo de la visión de Torretti existe un rechazo a la idea de que la verdad de las teorías científicas consista en su correspondencia con el mundo. Propongo entonces entender la correspondencia como una noción metafórica. Articularé una noción de coherencia pragmática sobre la cual establezco una nueva teoría de la coherencia entre verdad y realidad. En consecuencia, resultará posible afirmar que el realismo pragmático

\footnotetext{
* Recibido: octubre 2016. Aceptado: noviembre 2016.

This paper is partly based on a presentation entitled "Pragmatist Coherence as the Source of Truth and Reality," given at the sixth biennial conference of the Society for Philosophy of Science in Practice (SPSP) on 17 June 2016 at Rowan University. It also draws from presentations given at the fifth biennial conference of SPSP on 25 June 2015 at Aarhus University, and the Philosophy Masterclass lectures delivered at Bielefeld University in May 2016.

** Department of History and Philosophy of Science, University of Cambridge. Cambridge, United Kingdom. Email: hc372@cam.ac.uk
} 
consiste en la búsqueda del verdadero conocimiento de la realidad, de un modo que también concuerda con el pragamatismo defendido por Torretti.

Palabras clave: pragmatismo, realismo, pluralismo, coherencia, verdad, realidad.

In his paper "'Scientific Realism' and Scientific Practice" Roberto Torretti (2000: 114) advocates a position that he calls "pragmatic realism" following Hilary Putnam. He holds Putnam up as an exemplary philosopher who had sufficient wisdom to allow himself to be dissuaded away from standard scientific realism, to which Putnam had contributed iconically by articulating a popular version of the "no miracles" argument. As Torretti points out, Putnam (1987: 17) mused that he should have used the phrase "pragmatic realism" instead of "internal realism" to designate his mature position on realism.

This appears to be an aspect of Torretti's work that is very significant yet not widely known. The aim of my paper is to give a brief exposition of pragmatic realism as he has stated, and then to attempt a further development of it. The more elaborated position is my own, and I do not know whether Professor Torretti would agree with its details. However, what I can say with confidence is that my thinking has been significantly influenced by the process of studying his work.

To Torretti it is, in a sense, obvious that realism and pragmatism pull in the same direction, the Latin res and the Greek pragmata both having the same meaning, namely, "things" (Torretti, 2000: 113). So "pragmatic realism" is in fact a redundant phrase, a pleonasm. Realists are concerned about having correct knowledge of things; so are pragmatists. He states that science is "the continuation of common sense by other means" (ibid., 114-115), reflecting the insistence by John Dewey and other pragmatists that the process of inquiry is continuous from everyday life to the most esoteric branches of science. In all cases, knowledge is about getting on in the world, dealing with our situation in the most effective way possible. 


\section{Away from the mirage of correspondence}

We live in the world, and knowledge is only meaningful from that perspective within the world. It is a futile and pernicious philosophical dream to find an "external" perspective from which we can tell the real shape of the world. Torretti (2000: 114) blasts the "scientific realists" who believe "that reality is well-defined, once and for all, independently of human action and human thought," yet "in a way that can be adequately articulated in human discourse." They hold that science aims to develop "just the sort of discourse which adequately articulates reality — which, as Plato said, 'cuts it at its joints' - , and that modern science is visibly approaching the fulfilment of this aim." He confesses that he finds it difficult "to accept any of these statements or even to make sense of them."

He suspects, and I agree, that such "realism" is a religious hangover: "The existence of a well-defined or - as Putnam called it - ready-made reality is no doubt implied by the standard monotheistic conception of God, but I have not the slightest ground for thinking that God's worldview can be articulated in human discourse. To entertain the notion that we could convey that view in words is a symptom of acute provincialism." Such a view is something that a mature philosophy of science ought to be able to transcend: "it is pragmatic realism, not the nostalgic kryptotheology of 'scientific realism', that best expresses the real facts of human knowledge and the working scientist's understanding of reality." (ibid., 115) Torretti maintains that "science as it is actually practiced" is not concerned with looking for an "absolute structure" of reality (ibid., 117). He once recalled with pleasure: "During the Winter of 1983/84 I shocked my young Australian friend John Norton when I told him - as we stepped into the elevator of the Pittsburgh Center for the Philosophy of Science - that 'it is not the business of science to establish beliefs, let alone to deal in them.' Science is no belief-monger, like the Church." It is quite apt that this conversation should have taken place at the "Cathedral of Learning" at the University of Pittsburgh!

But there is more than just the hangover of monotheism that promotes the scientific realist's view of knowledge as correspondence to external reality. I believe that the traditional philosophical idea of scientific theory "representing" the external world is a deep-seated and pervasive metaphor, grounded in other human epistemic activities that are actually representational. Suppose we see an object and make a drawing of it; here we can say straightforwardly that the drawing represents the object. We can check how well it represents the

\footnotetext{
${ }^{1}$ Roberto Torretti to Hasok Chang, private communication, 26 September 2012.
} 
object by comparing how the object looks and how the drawing looks. We have direct access to both, and we can easily compare them with each other. ${ }^{2}$ This is not at all the kind of situation when we talk about the relation between a theory and the world. We have no direct access to "the world", if by that we mean things-in-themselves or noumena in Kantian terminology. And if something is not presented to us in the first place, we cannot re-present it.

The very idea of the "external world" is a metaphor (outside of what?), grounded in the phenomenal objects that we observe and make representations of. As Ian Hacking says (1983: 141-142), the notion of reality is "parasitic upon our practices of representation." ${ }^{3}$ The external world is a metaphor created by imagining that there must be something that a theory represents, even when we haven't made the theory by actually representing anything we know. After the mental creation of the metaphorical object, the rest of the metaphorical structure follows easily: the theory represents the imagined object, through some sort of correspondence between various aspects of the theory and various imagined properties of the imagined object. This metaphorical correspondence is the elusive "truth" sought by scientific realists.

I dare to think that the main message I am trying to convey is as simple as the Emperor of the well-known fairytale wearing no clothes: if the state of the world is completely independent of humans, then we cannot have any access to it; the common talk of representing-the-world and correspondenceto-the-world is metaphorical, not literal. Numerous eminent philosophers, such as Immanuel Kant, Ernst Cassirer, and the Vienna Circle have made similar points. The pragmatists were quite explicit in their objection to the "copy theory" of knowledge. Here is a memorable statement from William James (1978 [1907]: 96):

The popular notion is that a true idea must copy its reality. Like other popular views, this one follows the analogy of the most usual experience. Our true ideas of sensible things do indeed copy them. Shut your eyes and think of yonder clock on the wall, and you get just such a true picture or copy of its dial. But your idea of its 'works' (unless you are a clock-maker) is much less of a copy, yet it passes muster, for it in no way clashes with reality. Even tho

\footnotetext{
${ }^{2}$ For the purpose of this paper, the dictionary meaning of "metaphor" is good enough: "a figure of speech containing an implied comparison, in which a word or phrase ordinarily and primarily used of one thing is applied to another" (Webster's New World Dictionary, 1991).

${ }^{3}$ I thank Rasmus Winther for alerting me to this statement from Hacking.
} 
[sic] it should shrink to the mere word 'works,' that word still serves you truly; and when you speak of the 'time-keeping function' of the clock, or of its spring's 'elasticity,' it is hard to see exactly what your ideas can copy.

Clarence Irving Lewis (1929: 162) was equally emphatic, and more concise: "Knowledge does not copy anything presented. It proceeds from something given toward something else. When it finds that something else, the perception is verified."

The notions of representing-the-world and correspondence-to-the-world serve as serious obstacles in the philosophical understanding of scientific practices. Metaphors often do have useful functions to serve, but these particular metaphors have done more harm than good. The concepts of the external world, representation and correspondence, as they normally occur in philosophical discussions, are not only metaphors, but dead metaphors - that is a technical term referring to metaphors that are so ingrained in our way of talking that they are routinely mistaken as literal expressions. ${ }^{4}$ For example, as George Lakoff and Mark Johnson point out, we say that the temperature of a room is going "up" and that we are feeling "down" today, as if there were something inherently vertical about warmth or sadness. We may do harm by taking a metaphor literally, like the people who declared the so-called "war on drugs" and began to behave as if they were conducting a real war. ${ }^{5}$ Now, in some scientific and quotidian situations dead metaphors may serve as useful blinkers. But it is difficult to imagine situations in philosophy in which lack of awareness would be beneficial. In philosophy, I would argue, metaphors are only useful if they are employed consciously.

The representational metaphors I am speaking of here seem not only dead, but also un-dead: it seems impossible to kill them, no matter how many eminent philosophers attempt to do so. They continue to project the mirage of transcendental truth that science must seek, providing standard scientific realism with its seemingly inexhaustible intuitive fuel. The metaphors of representation and correspondence concerning the world have led to a perversion of the notions of something being "true" or "real." These notions are perfectly meaningful in the phenomenal realm of representing and

\footnotetext{
${ }^{4}$ See Bowdle and Gentner (2005). Wikipedia defines it as follows: "A dead metaphor is a figure of speech which has lost the original imagery of its meaning due to extensive, repetitive, and popular usage .... generally the result of ... the literalization of a metaphor."

${ }^{5}$ Another problem with dead metaphors is that they no longer serve the creative and exploratory functions of metaphors, discussed by Mary Hesse (1996) and Gerald Holton (1986) among others, which require awareness that the expression in question is not literal.
} 
intervening, and they should stay in that realm. We need to look away from the correspondence theory of truth, and look instead to J. L. Austin and "how to do things with words" (1962). Then a statement being true will mean that it passes all the tests of correctness that we can apply, as when you say: "Is it true that there is an airport in Cambridge?" (There is.) We know exactly how to answer that question, and how to double-check the answer as needed. As Putnam (1995: 10) put it succinctly, paraphrasing William James: "Truth... must be such that we can say how it is possible for us to grasp what it is."

\section{Pragmatist coherence}

We can retool the notions of truth and reality so that they become operable; thereby we can reclaim these key concepts for the use of people who are actually engaged in the production and improvement of empirical knowledge. At the heart of the reorientation I am proposing is the notion of pragmatist coherence.

What I mean by pragmatist coherence is not what epistemologists usually mean by "coherence". In the most simple-minded version of the coherence theory of truth, coherence is taken to mean mere logical consistency within a set of statements. This is nothing short of a philosophical disaster, an invitation to vicious circularity and the most problematic kind of relativism; it eliminates any inherent link between knowledge and reality. James O. Young (2015) notes that a more plausible version of the coherence theory "states that the coherence relation is some form of entailment. . . Another more plausible version . . . is that coherence is mutual explanatory support between propositions." A similar thought to Young's latter formulation is expressed by Richard Foley (1998: 157): "Coherentists deny that any beliefs are selfjustifying and propose instead that beliefs are justified in so far as they belong to a system of beliefs that are mutually supportive." But the problems of circularity and relativism remain in the idea of propositions rendering one another true by mutual support without anything else to ground any of them.

What I propose instead is a re-vitalized pragmatist notion of "coherence", implicit in John Dewey's theory of knowledge, which is irreducible to logical relations between statements. I define (pragmatist) coherence as a harmonious fitting-together of actions that leads to the successful achievement of one's aims. Such coherence may be exhibited in something as simple as the correct coordination of bodily movements needed in riding a bicycle, lighting a match, or walking up the stairs (very difficult to achieve, as we have learned in contemporary robotics), or something as complex as the successful 
integration of a range of material technologies and various abstract theories in the operation of the global positioning system (GPS). A coherent epistemic activity achieves its aim well, and avoids performative self-contradiction. When we do not heed the sign that warns "watch/mind your step", that rare moment of stumble reminds us how carefully and how well we normally maintain the coherence of our bodily movements in everyday life without even thinking about it.

Pragmatist coherence pertains to an activity, not to a set of propositions. It is defined in relation to the aims of the activity in question. Coherence is the chief characteristic of a successful activity; in fact, coherence and success are pretty much synonymous (though I also want to leave open the possibility of conceiving coherence as the cause of, or the explanation for, success). It should go without saying that pragmatist coherence cannot be achieved by wishful thinking or mere interpersonal agreement. In order to do things successfully in the world, we need to have an understanding or mastery of our surroundings. It is pragmatist coherence, not the mirage of correspondence, that is the vehicle through which the mind-independent world is brought to bear on our knowledge. Pragmatist coherence carries within it the constraint by nature. In fact, having cleared away the ungrammatical illusion of a direct correspondence between proposition and reality, we can see that pragmatist coherence is the only way in which reality can enter knowledge, the only way in which reality can bear on our practices. (This is also part of the definition of "reality", as we will see.)

To help us think about pragmatist coherence, I propose that we take Neurath's boat, literally: "We are like sailors who have to rebuild their ship on the open sea, without ever being able to dismantle it in dry-dock and reconstruct it from the best components." (Neurath, 1983 [1932/33]: 92) This is usually taken as a splendid coherentist metaphor for the fitting-together of propositions. But let's try seeing the boat, or rather boat-fixing, as a particular situation illustrating the nature of pragmatist coherence. Is the boat sufficiently water-tight? Can it be made tighter by piecemeal engineering? The "coherence" of what we do with the boat here is not conceived in an absolute way, as logical consistency would be. Rather, it is defined with respect to a very particular purpose, namely keeping the boat afloat. 


\section{A new coherence theory of truth}

If coherence is the property of an activity, how does it relate to truth, which is the property of a statement or a proposition? This is a significant and difficult question, but let me at least provide a sketch of an answer. The "pragmatic theory of truth" attributed to James is widely regarded as absurd, and this has contributed greatly to the unpopularity of pragmatism among tough-minded philosophers. Here is probably the most notorious statement by James (1978 [1907]: 106): "The true', to put it very briefly, is only the expedient in the way of our thinking, just as 'the right' is only the expedient in the way of our behaving. Expedient in almost any fashion ..."

I think James's choice of the word "expedient" here was unfortunate, sounding too much like mere "convenience" or "usefulness". Possibly, the word had quite a different connotation back then; that is for real James scholars to debate. What I want to do is propose a different formulation, in terms of my notion of coherence: A statement is true in a given circumstance if (belief in) it is (necessarily) involved in a coherent epistemic activity. What I mean by an "epistemic activity" is a set of mental or physical operations that are intended to contribute to the production or improvement of knowledge in a particular way, in accordance with some discernible rules. ${ }^{6}$

The epistemic activity involved in the definition of truth does not have to be that of explicit theory-testing. Sometimes a true statement is explicitly verified; other times its truth consists in its involvement in other kinds of successful activities. One thing to note is that if truth is defined in terms of coherence, it has to be a matter of degree, and I think that is right. And the truth of a statement acquired in one epistemic activity may be extended through involvement in other coherent epistemic activities; therefore truth is a matter of scope as well as degree.

The statement quoted above from James actually continues as follows, which tends to confirm my reading of him: “. . . and expedient in the long run and on the whole of course; for what meets expediently all the experience in sight won't necessarily meet all farther experiences equally satisfactorily. Experience, as we know, has ways of boiling over, and making us correct our present formulas." The last bit of James's statement actually fits very well with my notion that pragmatist coherence is the only way in which reality gives input into our knowledge. And this gives coherentist truth the mind-

\footnotetext{
${ }^{6}$ For further discussion of epistemic activities (and also what I call systems of practice), see Chang (2014). It may not be necessary to specify the activity in question as epistemic, but it would be a reasonable restriction to make within the philosophy of science.
} 
independence that realists value most in correspondence truth, while it is an "internal" notion meaningful within a system of practice, not without it. Such a conception of truth easily allows plurality while avoiding arbitrariness.

There is one part of my definition that will definitely raise some worries: belief in a statement may be involved in a coherent activity in a superfluous way (in a way reminiscent of the tacking paradox or the Gettier problem). How do we solve this problem of impostor propositions? There is no magic solution. As Clarence Irving Lewis (1930: 14) put it in his review's of John Dewey's The Quest for Certainty: "Salvation is through work; through experimental effort, intelligently directed to an actual human future."

That is to say, in testing the truth of a proposition, we need to check for (pragmatist) necessity: can the coherence of the activity be maintained, can the aims of the activity still be achieved, if we negate the proposition is question? For example, we can work with Maxwell's equations while denying that the ether exists, so we can argue that belief in the existence of the ether is superfluous in relation to the coherence of the activity of solving Maxwell's equations, even though it was not superfluous in Maxwell's original activity of model-building which led him to the equations in the first place. Checking for pragmatic necessity is nothing more grand than Mill's method of difference. It may not live up to some overblown image of a philosophical solution, but it is how we get on in science, and in the rest of life, too.

A quick illustration of how this pragmatist coherentist notion of truth works out may be useful. Take the proposition that is perhaps the most important in the history of organic structural chemistry in the 19th century: "Carbon has valency 4," meaning that it was capable of forming 4 bonds with other chemical units (atoms or radicals). This statement was involved in the successful working-out of numerous molecular structures. It was also involved in the understanding and execution of substitution reactions; for example, it was possible to make a body of methane gas $\left(\mathrm{CH}_{4}\right)$ absorb a volume of chlorine gas and emit an equal volume of hydrogen gas, turning the methane into chloromethane $\left(\mathrm{CH}_{3} \mathrm{Cl}\right)$. Such a substitution could be made four times in total, in the end yielding carbon tetrachloride $\left(\mathrm{CCl}_{4}\right)$. Such successes, it is fair to say, constitute the truth of "Carbon has valency 4." But this truth was a limited one. We know, for example, that the structure of carbon monoxide remained a mystery for a long time. Even carbon dioxide was not trivial to understand, but it could be accommodated by saying that the carbon atom formed a double bond with each of the two oxygen atoms it was combined with $(\mathrm{O}=\mathrm{C}=\mathrm{O})$, thereby using up all of its 4 bonding-potentials. But it was not clear at all how carbon monoxide $(\mathrm{CO})$ could be understood. 
My new coherence theory of truth is ultimately indistinguishable from James's pragmatist theory of truth freed from misunderstandings. According to this conception, if our use of a theory has led to successful outcomes and not as a result of any strange accident or coincidence as far as we can see, then we can and should say, modestly and provisionally, that the relevant statements made in this theory are "true" — in the same sense as we say that it is true that rabbits have whiskers and live in underground burrows. This "truth" is operational and verifiable. It is the same thing as empirical confirmation, taken in a broad sense. It is achievable, to various degrees, and its pursuit is clearly useful.

\section{A coherence theory of reality}

So far I have been speaking loosely about "reality", and it is now time to give a more precise pragmatist characterization of that notion. In a similar way to how I have defined truth, pragmatist coherence can also ground an operative notion of reality. The easiest way to see this is to start with Ian Hacking's "entity realism": "If you can spray them, then they're real." (Hacking, 1983: 23) He adds: "One can believe in some entities without believing in any particular theory in which they are embedded." (ibid., 29)

Concepts enabling successful investigations deserve our realist confidence. I propose a coherence theory of reality: a putative entity should be considered real if it is employed in a coherent epistemic activity that relies on its existence and its basic properties (by which we identify it). This notion of reality (or real-ness) might be written with a lowercase " $r$ " in order to distinguish it from the idea of "Reality" that denotes the whole "world", or some transcendent existence. Like truth in my pragmatist coherentist conception, "small-r" reality comes in different degrees, and is defeasible, as it is based on coherence. ${ }^{7}$

There is an obvious objection to Hacking-type stance, which is actually a blessing in disguise: might we not misunderstand our experiments, presuming that some non-existent entity is involved in it? This seems to have happened with some regularity in the history of science. For example, Joseph Priestley claimed to be able to manipulate phlogiston, and one cannot deny that most of his numerous experiments were successful. In the 1770s he made an attempt to "de-phlogisticate" air by reducing a calx (rust) back into metallic form in an enclosed space; the air in that space would give up its phlogiston to the

\footnotetext{
${ }^{7}$ C. I. Lewis (1929: chapter 7) employed this device of distinguishing "Reality" and "reality" for similar purposes.
} 
calx, restoring its metallic nature. This seemed to work out, as he obtained a gas that supported combustion exceptionally well; air deprived of its phlogiston would be eager to absorb phlogiston from a combustible substance (which is combustible precisely because it contains plenty of phlogiston that can be removed). This is how Priestley first made the gas that was later dubbed "oxygen" by Antoine Lavoisier. In a less ambiguous experiment, he predicted that a calx could be reduced by heating in inflammable air (later called hydrogen), which he conceived as pure phlogiston. This experiment succeeded brilliantly. Did Priestley's successes mean that he and his contemporaries should have granted reality to phlogiston? In short, my answer to that question is yes. ${ }^{8}$

William Herschel's discovery of infrared radiation in 1800 supplies a simpler example, though not as satisfyingly outrageous. ${ }^{9}$ Having used a prism to make a rainbow-like spectrum from the sunbeam, Herschel found that a thermometer inserted into the dark space beyond the red end of the spectrum detected a good deal of heating effect. According to our modern understanding, Herschel discovered that low-frequency electromagnetic radiation is not detectable by the eye but has a heating effect. That is not how Herschel and many of his contemporaries saw his achievement: they thought that he was using a prism to separate out the rays of caloric (Lavoisier's substance of heat) and the rays of light in the sunbeam. In that interpretation, Herschel successfully directed caloric rays onto the thermometer to raise the temperature. If this doesn’t qualify as “spraying," I don't know what does.

I will invoke just one more example, which is quite well-known. Not only a great deal of theoretical explanations but numerous experimental interventions in modern chemistry rely on the concept of orbitals and on the detailed knowledge of the number and shapes of various types of atomic and molecular orbitals. But orbitals inhabited by individual electrons have no reality if we take quantum mechanics literally, since all electrons are identical and they cannot be said to occupy different orbitals within a given atom or molecule. Yet, it makes sense to attribute reality to orbitals, on the basis of the successful chemical practices employing them.

Now, don't these cases just amount to a refutation of Hacking's view on realism and my definition of reality, since we know that phlogiston, caloric, and orbitals aren't real? But this response is question-begging: how do we know that such entities are not real? On the other hand, why do we think

\footnotetext{
${ }^{8}$ See Chang (2012: chapter 1) for a detailed discussion of the phlogiston case.

${ }^{9}$ See Chang and Leonelli (2005) for details on this case.
} 
anything is real? In this context Hacking (1983: 189), with unlikely help from George Berkeley's A New Theory of Vision, points out that even our normal 3 -D vision concerning "medium-sized dry goods" is only acquired through a conjunction of the senses of vision and muscular tension (involved in moving around and picking things up); Berkeley also reminds us that focusing at various distances involves muscular tension in the eye. What this suggests is that our intuition about reality at the most basic level is based on coherence: in this case, a harmonious convergence of different modalities of sensation in the course of our daily lives. ${ }^{10}$

In a similar way, phlogiston within its domain of successful use is as real as tables-and-chairs and cats-and-dogs are in our daily lives. At the basis of this assessment is the notion of pragmatist coherence. Let's consider more carefully what it really means to say "X is real." In a previous publication (Chang, 2012: chapter 4) I saw "Reality" as nature itself, something mindindependent, something that can resist our attempts to deal with it in some particular way that we might prefer. But this sense of "Reality" is like the Kantian thing-in-itself, about which we can and should say nothing. I also advanced a doctrine of "active realism," which is a commitment to learn as much as possible about Reality. But that makes no sense if Reality itself is something one can't say anything about. So I was talking nonsense.

When Hacking says that positrons are real, or when I say phlogiston is real, the sense of it is that a specific part or aspect of that unspecified overall Reality is somehow being captured in our conception. And this parsing-out of Reality is crucial in any kind of cognitive activity. If we cannot identify sensible parts (or aspects) of nature, we cannot say anything intelligible, make any kind of analysis, or engage with nature in any specific and directed way. So we have no choice but to worry about whether we are able to do the parsing well. ${ }^{11}$ But how can we ever tell whether we have done it correctly? Again, "salvation is through work" - we can never be absolutely sure, but we check, double-check, and try checking in new domains of phenomena.

\footnotetext{
${ }^{10}$ Richard Held (1965) conducted experiments that seemed to show that normal vision failed to develop when kittens were deprived of muscular activity moving themselves around.

${ }^{11}$ So, in a sense, a kind of entity realism is prior to any truth-realism one might hope for.
} 


\section{Pluralism and pragmatic realism}

The criterion of coherence rules out many things, but also rules in many things. In the absence of what else we might operationally mean by "real", and with the recognition that this concept of reality is not something we can do without, we should have the courage to admit that a lot of different kinds of things are real, even if the concepts pointing to them belong to mutually incommensurable systems of practice. So here I end with a modest sort of metaphysical pluralism.

This is in line with pragmatic realism in Torretti's rendering, which comes with a distinctly pluralist flavor. And he is not alone. Israel Scheffler (1999) has made a plea for a pluralist realism, which he calls "plurealism". John Dupré (1993) has advocated a "promiscuous realism". And as Putnam (1987: 21) reminds us, there is a much longer and very respectable pedigree of "ontological relativity":

Quine has urged us to accept the existence of abstract entities on the ground that these are indispensible in mathematics, and of microparticles and spacetime poits on the ground that these are indispensible in physics; and what better justification is there for accepting an ontology than its indispensibility in our scientific practice? he asks. Goodman has urged us to take seriously the metaphors that artists use to restructure our worlds, on the ground that these are an indispensible way of understanding our experience. Davidson has rejected the idea that talk of propositional attitutdes is 'second class', on similar grounds.

Professor Torretti, while commenting very favorably on my 2012 book Is Water $\mathrm{H}_{2} \mathrm{O}$ ?, chided me for not going strongly against metaphysical monism: "I regret that you do not clearly and emphatically chastise ... the assumption that 'reality' consists of one definite set of bits, that there is one and only one 'correct' way of cutting up the unstopping flow of phenomena into bits. Indeed, if there were such a unique set of well-defined and not further and diversely analyzable bits, one might reasonably expect each bit to carry just one truth." ${ }^{\prime 2}$ Metaphysical pluralism, of course, is an important counterpart to epistemological pluralism. I aspire to do better in this regard in my future work, starting with the present paper.

Torretti argues that "the way that scientific theories succeed and displace one another provides strong grounds for doubting the scientific realist's belief

\footnotetext{
12 Roberto Torretti to Hasok Chang, private communication, 26 September 2012.
} 
that science is getting ever closer to achieving an adequate grasp of the selfsubsisting, uniquely defined structure of reality." He particularly draws our attention to "the manner in which conceptually disparate theories are jointly brought to bear on the understanding of specific phenomena and the solution of particular problems." (Torretti, 2000: 117) As often is the case, Torretti's inspiring examples come from modern physics, yet they give us insights that are not normally taken from modern physics.

In the first of the two cases that Torretti highlights, Stephen Hawking worked out the "evaporation" of black holes by applying the notion of quantum tunneling to them. This was a very successful move, but not a credible one if seen from the monist realist point of view. Hawking successfully pulled together certain specific aspects of general relativity and quantum mechanics with no guarantee that the two theories could be unified or even reconciled with each other on the whole. Torretti says (2000: 117): "Hawking's work on evaporating black holes ... combines disparate theories, I dare say, outrageously." In the second case, Torretti challenges the received wisdom on the great success of the general theory of relativity in explaining the perihelion shift of mercury (ibid., 118-119). Applying Newtonian theory, with no regard to general relativity, acounted for the shift of 530" per century. The remaining 43" per century was obtained from a solution of the general relativistic field equation, but in reaching that solution "the relativists simply ignored the 530" secular precession." In Torretti's analysis, this amounted to "bringing to bear on [the problem] two conceptually very different theories, irreconcilable in God's eye". Such cases abound in modern scientific practice, as Sandra Mitchell (2003) has stressed in support of her doctrine of "integrative pluralism" arising from her study of complex biological systems.

When the pragmatist coherentism sketched here is fully developed, people committed to a realistic understanding of scientific pratice will be able to re-claim the notions of truth and reality, which are actually useful terms in ordinary language as well as scientific discourse. ${ }^{13}$ This will help us in the task of making detailed and systematic studies of scientific practice while not dispensing with concerns about truth and rationality. I take inspiration from Kant's view of the "Copernical Revolution" that he saw himself making in philosophy (Kant, 1933 [1781]: 22/B xvii): "If intuition must conform to the constitution of the objects, I do not see how we could know anything of the latter a priori; but if the object must conform to the constitution of our faculty of intuition, I have no difficulty in conceiving such a possibility." In a similar

\footnotetext{
${ }^{13}$ I plan to articulate this perspective in detail in a book entitled Realism for Realistic People.
} 
way, we may say in relation to pragmatist coherentism concerning truth and reality: it is not that our activities are coherent because our theoretical entities are real and our theoretical propositions are true; rather, we regard as real and true the entities and statements that underpin coherent activities.

\section{References}

Austin, J. L. (1962). How to do things with words. Oxford: Clarendon Press.

Bowdle, B. F. \& Gentner, D. (2005). “The career of metaphor”. Psychological Review, 112, 193-216.

Chang, H. (2012). Is water $\mathrm{H}_{2} \mathrm{O}$ ? Evidence, realism and pluralism. Dordrecht: Springer.

Chang, H. (2014). "Epistemic activities and systems of practice: Units of analysis in philosophy of science after the practice turn". In L. Soler, S. Zwart, M. Lynch, \& V. Israel-Jost (Eds.), Science after the practice turn in the philosophy, history and social studies of science (pp. 6779). London and Abingdon: Routledge.

Chang, H. \& Leonelli, S. (2005). "Infrared metaphysics: The elusive ontology of radiation (part 1)". Studies in History and Philosophy of Science, 36, 477-508.

Durpé, J. (1993). The disorder of things: Metaphysical foundations of the disunity of science. Cambridge, MA: Harvard University Press.

Foley, R. (1998). "Justification, epistemic". In E. Craig (Ed.), Routledge Encyclopedia of Philosophy (vol. 5, pp. 157-165). London: Routledge.

Hacking, I. (1983). Representing and intervening. Cambridge: Cambridge University Press.

HeLd, R. (1965). "Plasticity in sensory-motor systems". Scientific American, 213 (5), 84-94.

Hesse, M. (1966). Models and analogies in science. Notre Dame: University of Notre Dame Press.

Holton, G. (1986). "Metaphors in science and education". In G. Holton, The advancement of science, and its burdens (pp. 229-252). Cambridge: Cambridge University Press, 1986.

James, W. (1978 [1907]). Pragmatism and The meaning of truth. Cambridge, MA: Harvard University Press. 
Kant, I. (1933 [1781]). The critique of pure reason, 2nd ed. Trans. by N. Kemp Smith. London: Macmillan.

LaKoff, G. \& Johnson, M. (1980). Metaphors we live by. Chicago: University of Chicago Press.

LewIS, C. I. (1929). Mind and the world-order: Outline of a theory of knowledge. New York: Dover.

Lewis, C. I. (1930). [Book review] "The quest for certainty: A study of the relation of knowledge and action [by] John Dewey". The Journal of Philosophy, 27, 14-25.

Mitchell, S. D. (2003). Biological complexity and integrative pluralism. Cambridge: Cambridge University Press.

Neurath, O. (1983 [1932/33]). "Protocol Statements". In R. S. Cohen, \& M. Neurath (Eds.), Philosophical papers 1913-1946 (pp. 91-99). Dordrecht: Reidel.

Putnam, H. (1987). The many faces of realism. Chicago and La Salle: Open Court.

Putnam, H. (1995). Pragmatism: An open question. Oxford: Blackwell.

SCHEFfler, I. (1999). “A Plea for Plurealism”. Transactions of the Charles $S$. Peirce Society, 35, 425-436.

Torretti, R. (2000). “'Scientific realism' and scientific practice”. In E. Agazzi \& M. Pauri (Eds.), The reality of the unobservable (pp. 113122). Dordrecht: Kluwer.

Young, J. O. (2015). “The coherence theory of truth". In E. N. Zalta (Ed.), Stanford encyclopedia of philosophy. http://plato.stanford.edu/entries/ truth-coherence/. 